\title{
DO WEATHER AND MOON HAVE ANY INFLUENCE ON SPOTLIGHTING MAMMALS? THE CASE OF HARE IN UPLAND ECOSYSTEM
}

\author{
SOKOS, C. ${ }^{1,2,3^{*}}$ - PAPASPYROPOULOS, K. G. ${ }^{3}-$ BIRTSAS, P. ${ }^{3,4}-$ \\ GIANNAKOPOULOS, A. ${ }^{1}-$ BILLINIS, $^{1,2}{ }^{1,2}$ \\ ${ }^{1}$ Laboratory of Microbiology and Parasitology, Faculty of Veterinary Medicine, University of \\ Thessaly, Trikalon 224, 43100 Karditsa, Hellas (Greece) \\ ${ }^{2}$ Department of Biomedicine, Institute for Research and Technology of Thessaly, Centre for \\ Research and Technology Hellas (CERTH), Larissa, Hellas
}

${ }^{3}$ Research Division, Hunting Federation of Macedonia and Thrace, Ethnikis Antistasis 173-175, 55134 Thessaloniki, Hellas

${ }^{4}$ Laboratory of Wildlife, Department of Forestry and Management of Natural Environment, Technological Institute of Thessaly, End of Mavromichali Str., 43100 Karditsa, Hellas

*Corresponding author

e-mail:sokos@vet.uth.gr

(Received $18^{\text {th }}$ Nov 2014; Accepted $19^{\text {th }}$ Dec 2014)

\begin{abstract}
Nocturnal spotlight survey is a common census technique for many mammal species. The influence of abiotic factors may be essential for the appropriate design of censuses, however this method has not been examined sufficiently in relation to abiotic factors such as weather conditions and the moon. We tested their influence for a commonly counted species, the brown hare (Lepus europaeus). Spotlight surveys were conducted at certain night time and transects in three upland Mediterranean areas, at different times of the year, different moon phases and under a variety of weather conditions. Wind speed and direction had an influence on hare counts with stronger winds resulted in fewer juvenile hares being observed, and more hares were counted when wind was blowing from the hare towards the vehicle. No significant effects were found from the other factors probably due to the intense relief and thick vegetation of the studied areas.
\end{abstract}

Keywords: activity, abundance, census method, lagomorphs, mammals.

\section{Introduction}

Spotlighting (spotlight count or night lighting) is widely used to survey mammals during night (Scott et al., 2005; Sunde and Jessen, 2013). This is a favored method of estimating abundance due to its efficiency, repeatability and no necessity for animals capture (Langbein et al., 1999). However, numerous studies have shown that several factors can affect the spotlight counts of mammals. These include the animal's activity patterns and behaviour (Brown and Peinke, 2007), visibility (Parkes, 2001; Barnes and Tapper, 1985), relief and amount of vegetation cover (Ralls and Eberhardt 1997; Langbein et al., 1999; Tizzani et al., 2013), observer experience (Sunde and Jessen, 2013), time of night and moonlight (Langbein et al., 1999; Scott et al., 2005) and weather conditions (Langbein et al., 1999).

Spotlighting is a very common survey method for lagomorphs (Strauß et al., 2008; Tizzani et al., 2013) and studies reveal sources of variation in counts due to weather conditions and moon phase. Newman (1959) found that the number of cottontails (Sylvilagus floridanus) observed during early morning or late afternoon roadside counts was higher with increasing 
snow cover, frost, rain preceding the count, and decreasing temperature and wind speed. In contrast significantly fewer brown hares were spotlighted when the temperature fell below $15^{\circ} \mathrm{C}$ in Britain (Barnes and Tapper, 1985). Heydon et al. (2000) found no influence of rain or visibility on brown hares counted in Britain. Fafarman and Whyte (1979) refer that cottontail spotlight counts tended to be higher when rain was falling during the count and lower when moon illumination was increasing. Wind direction had also an influence, but no other weather factor affected their counts. In an arid region of Jordan, moonlight had a varied effect on spotlight counts of cape hare (Lepus capensis), but with similar densities during full and no moon (Scott et al., 2005).

The above results seem to be contradictory for some factors and inconclusive for some others; one explanation may be the differences in abiotic and biotic conditions between geographical areas and differences between lagomorph species behaviour. Therefore, there is currently a difficulty in designing a study that takes weather and moonlight effects into account; consequently, their influence is generally overlooked in hare spotlight counts (Strauß et al., 2008; Sunde and Jessen, 2013). In upland and shrubland ecosystems in particular we are unaware of any studies concerning the influence of abiotic factors on spotlighting brown hares. Thus, the objective of this study was to determine the influence of moonlight and weather conditions on the number of brown hares counted along spotlight transects.

\section{Materials and Methods}

\section{Study area}

The study was part of a larger research project on the influence of wildfires on brown hare that was carried out in the Kassandra Peninsula of Chalkidiki Prefecture, Macedonia, northern Hellas (Fig. 1).

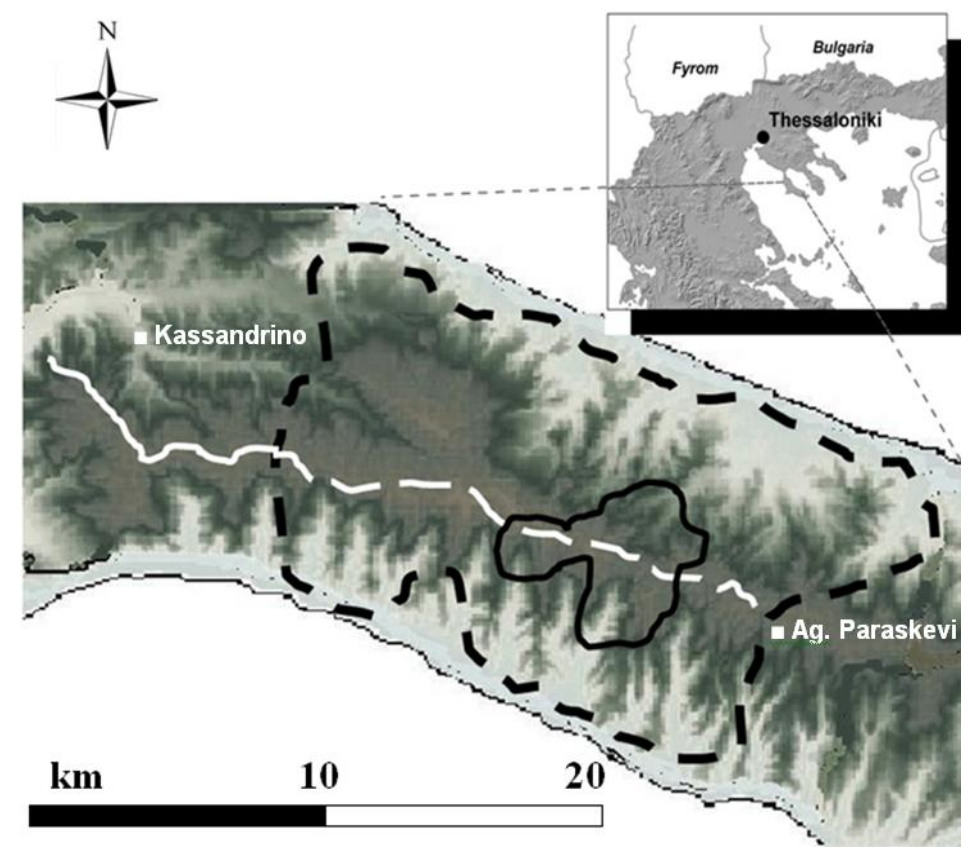

Figure 1. Location of the study area. The dashed black line indicates the moderately burned area and the solid black line denotes the intensely burned area. The solid white line shows the transect within the unburned area, and the dashed white line shows the two transects within the burned areas 
The Kassandra Peninsula has altitudes ranging 150-280 $\mathrm{m}$ above sea level, and the climate is Mediterranean with hot and dry summers, mild winters, and moderately rainy autumns and springs. Mean annual precipitation is $581 \mathrm{~mm}$ and the mean annual air temperature $16.3^{\circ} \mathrm{C}$. The landscape has intense relief with steep slopes in some positions.

The study area is covered mainly by forest vegetation of Aleppo pine (Pinus halepensis) and broadleaved shrubs (Quercus coccifera, Pistacia lentiscus, Phillyrea media, Cistus incanus), while there are also scattered agricultural fields, mainly comprising olive groves, cereal and few vetch crops. Wildfire occurred in Kassandra on $21 / 8 / 2006$ and burnt an area of $68.7 \mathrm{~km}^{2}$. The woody plants regenerated quickly after wildfire and shrubs resprouts reached the height of about half a meter in the first year after the wildfire.

The spotlight transects stretch along the ridge of the peninsula and the unsurfaced forest roads. The transects had a total length of $22 \mathrm{~km}: 8.5 \mathrm{~km}$ passing through unburned areas, $9.5 \mathrm{~km}$ through moderately burned areas, and $4 \mathrm{~km}$ passing through intensely burned areas (Fig. 1).

\section{Spotlight counts}

Hares were spotlighted in the study area at different times of the year, under different weather conditions and moon phases, but along the same transects and at the same time of night and all transects were surveyed each night. To avoid observer bias, almost the same crew undertook surveys in each visit. Hares were counted from a 4-wheel truck traveling at about $15-20 \mathrm{~km} / \mathrm{h}$ on forest roads. The crew consisted of the driver and two observers, each one holding two million candle spotlights which were used to light up both sides of the road. Surveys began two hours after sunset (Verheyden, 1991; Langbein et al., 1999). Visits were postponed during intensive rains and in thick mist. About one visit was carried out each month in spring and summer and two visits in autumn and winter. The survey lasted for two years during the first and second year after wildfire, and the total number of visits was 30 .

Additionally, as most of the hares were seen initially or were approached later at a distance of less than 30 meters, it could be distinguished which hares weighed more than $3 \mathrm{~kg}$ (developed hares) and which less than $2.5 \mathrm{~kg}$ (juvenile hares), that is younger than three months old (Bray et al., 2002). Those which could not be seen well or appeared intermediate in weight were not categorized.

\section{Weather conditions and moon phase}

According to the literature concerning influences on spotlight counts, we selected nine explanatory variables to describe the variable "hare counts" (Table 1). During each visit, wind level and cloud cover were recorded. Available climatic data for the study area on each visit day were obtained from the nearest climatic station of the National Observatory of Athens (http://penteli.meteo.gr/meteosearch/). Precipitation values of the visit day and two days before, the mean air temperature, wind speed and direction were taken into consideration in all analyses (Table 1). Moonlight illumination values for each day were obtained from the US Naval Observatory (http://aa.usno.navy.mil/data/docs/MoonFraction.html). The level of moonlight was adjusted by multiplying illumination of the moon and cloud cover according to Brown and Peinke (2007). Cloud cover was categorized as $1=$ no cloud cover, $0.5=$ intermediate, 
$0.1=$ complete cloud cover. We used 0.1 instead of zero for complete cloud cover, because the darkest of the nights with a full-moon was brighter than any new moon nights, as the moonlight penetrated the clouds (Griffin et al., 2005).

Table 1. Weather and moon variables and their values during the counts

\begin{tabular}{|c|c|c|c|c|c|}
\hline Variable & Meaning & Type & Mean \pm SE & Min. & Max. \\
\hline Moon & Degree of moon appearance during the visit & Scale & $0.42 \pm 0.07$ & 0 & 1 \\
\hline Clouds & Degree of cloud cover during the visit & Ordinal & $1^{\mathrm{a}}$ & 0.1 & 1 \\
\hline Moonlight & Interaction of moon and clouds during the visit & Scale & $0.28 \pm 0.06$ & 0 & 1 \\
\hline Temperature & Mean temperature on the day of the visit $\left({ }^{\circ} \mathrm{C}\right)$ & Scale & $13.4 \pm 1.55$ & 0 & 33.8 \\
\hline Rain1 & Precipitation during the day of visit $(\mathrm{mm})$ & Scale & $0.3 \pm 0.16$ & 0 & 4 \\
\hline Rain2 & $\begin{array}{l}\text { Precipitation during the day of visit and one day before } \\
(\mathrm{mm})\end{array}$ & Scale & $2.11 \pm 1.03$ & 0 & 23.6 \\
\hline Rain3 & $\begin{array}{l}\text { Precipitation during the day of visit and two days before } \\
(\mathrm{mm})\end{array}$ & Scale & $3.79 \pm 1.25$ & 0 & 23.6 \\
\hline Windspeed & Mean wind speed on the day of the visit $(\mathrm{km} / \mathrm{h})$ & Scale & $8.1 \pm 0.91$ & 1 & 22.7 \\
\hline Windir & Direction of wind on the day of the visit & Circular & east $^{\mathrm{b}}$ & - & - \\
\hline
\end{tabular}

\section{Statistical analysis}

The hares observed during each visit were divided into two categories, each one consisting of three dependent variables. The first category was relevant to the hares' age. It included the variable "juv" with the juvenile hares, the variable "dev" with the developed hares, and the variable "total" with the sum of counted hares. The second category was relevant to the study area. It included the variable "intBurned" with the observed hares/visit in the intensely burned areas, the variable "modBurned" with the observed hares/visit in the moderately burned areas, and the variable "unburned" with the observed hares/visit in the unburned areas. We also used an additional variable, "totBurned", which was the sum of "intBurned" and "modBurned" variables.

As shown in Table 1, our aim was to examine the influence of seven scales, one ordinal and one circular variable to the dependent variables. Circular variables have a special statistical analysis not suitable for the usual types of variables, and for this reason we transformed Windir into two variables sinWindir and cosWindir. That is, we followed the transformation suggested by Jammalamadaka and Lund (2006) by computing the sine and cosine of the wind angular measurement in order to use it in the typical statistical analysis of weather and moon data.

Firstly, descriptive statistical methods were used to analyze the data. We computed mean values, standard errors and median values of the variables. We then used the non-parametric Sign test. This test is robust to normality and homogeneity of variance and makes no assumptions about the original distributions of the variables (Gray and Kinnear, 2012). The test was used to examine if there was a statistical significant trend in hare counts due to hare abundance changes and other factors.

When a statistical significant difference was confirmed, we removed the trend from the series of observations. This is a common procedure in time series analysis (Box et al., 2008). To determine the real influence of the weather and moon variables on the hare population, one has to remove any existing population trend. In the time series $\left\{y_{t}\right\}_{t=1}^{n}$, the trend can be removed if we create a new time series $\left\{x_{t}\right\}_{t=1}^{n-1}$ using the 
equation (Chatfield, 2004): $x_{t}=y_{t}-y_{t-1}$. We used the Kendall tau-b correlation coefficient to relate the new series with the weather and moon variables. The analysis was performed using the statistical software IBM SPSS 20.0 and the significance level was set to $\mathrm{P}<0.05$ and tending towards significance at $\mathrm{P}<0.1$.

\section{Results}

A total of 30 visits to the study area identified 104 hares in a total distance of 660 $\mathrm{km}$. During the counts, the moon was usually below crescent, but in four visits it was around full moon and cloud cover was absent (Table 1). Mean daily temperature varied from zero in winter to $33.8^{\circ} \mathrm{C}$ in summer. There was no snowfall and rainfall was low on the day of the count, although for the period of two days before the visit, rainfall $>10 \mathrm{~mm}$ was recorded in five visits. A light breeze blew during most counts with a maximum speed of $22.7 \mathrm{~km} / \mathrm{h}$ (tree branches move).

The Sign test confirms that there is an increasing trend of observed hares in the second year after the wildfire in the intensely burned and the moderately burned areas of the study area $(\mathrm{P}=0.016$ and $\mathrm{P}=0.004$ respectively). The unburned areas show no trend $(\mathrm{P}=1.0)$. Therefore, the procedure of differencing was applied in order to eliminate the trends. An example in Fig. 2 shows the result of differencing the trended series. The left Figure shows the initial total count of hares, where a trend is confirmed, and the right Figure shows the detrended series.
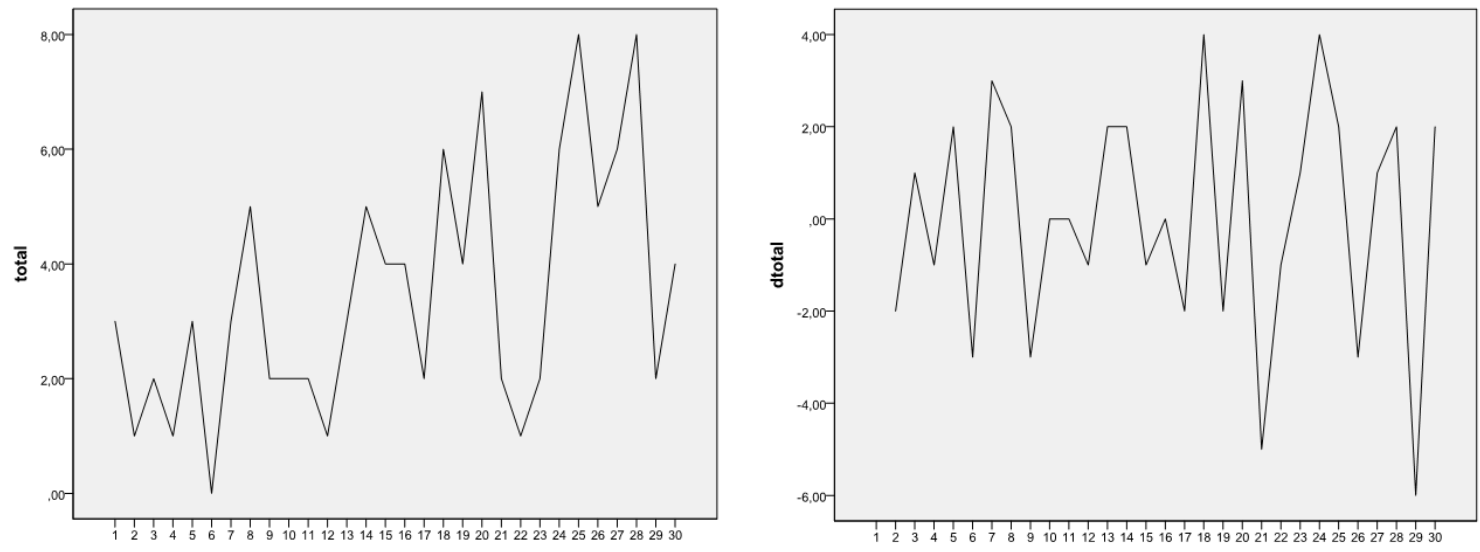

Figure 2. Initial (left) and detrended series (right) of hare counts during the 30 visits (total of counts from the three transects)

The detrended series were checked for their bivariate correlations with the weather and moon variables. Table 2 shows that significance at the $10 \%$ level was found between wind speed and the counts of juvenile hares, showing a negative linear correlation. This means that stronger winds resulted in fewer juvenile hares being observed (Fig. 3). This relationship is marked in bold in Table 2. Another marked relationship, the one between intensively burned areas and the sine of Wind Direction ( $\sin$ WD), indicates that east winds are coincided with an increased number of recorded hares. 
Table 2. Kendal's tau-b correlation coefficient of counted hares and weather and moon variables. The bold numbers mark significant relationships at the $P<0.1$ significance level

\begin{tabular}{ccccccccccc}
\hline Variable & moon & clouds & illumin & temp & rain1 & rain2 & rain3 & windspeed & sinWD & cosWD \\
\hline juv & 0.163 & 0.087 & 0.106 & 0.124 & -0.136 & -0.046 & -0.044 & $\mathbf{- 0 . 2 6 7}$ & 0.057 & 0.109 \\
$\mathrm{P}$ & 0.252 & 0.597 & 0.453 & 0.378 & 0.404 & 0.772 & 0.775 & $\mathbf{0 . 0 5 8}$ & 0.705 & 0.474 \\
\hline $\mathrm{dev}$ & -0.048 & -0.024 & 0.005 & -0.010 & -0.151 & 0.092 & 0.045 & 0.205 & -0.071 & 0.009 \\
$\mathrm{P}$ & 0.727 & 0.880 & 0.971 & 0.942 & 0.344 & 0.555 & 0.765 & 0.138 & 0.636 & 0.951 \\
\hline total & -0.115 & -0.063 & -0.144 & 0.026 & -0.161 & -0.158 & -0.006 & 0.026 & 0.202 & 0.032 \\
$\mathrm{P}$ & 0.403 & 0.690 & 0.295 & 0.849 & 0.306 & 0.310 & 0.967 & 0.849 & 0.172 & 0.831 \\
\hline intBurned & -0.194 & -0.012 & -0.215 & -0.041 & 0.102 & -0.158 & 0.127 & 0.163 & $\mathbf{0 . 3 0 0}$ & 0.047 \\
$\mathrm{P}$ & 0.184 & 0.943 & 0.141 & 0.775 & 0.544 & 0.340 & 0.420 & 0.261 & $\mathbf{0 . 0 5 7}$ & 0.765 \\
\hline modBurned & -0.115 & -0.080 & -0.085 & 0.057 & -0.110 & -0.214 & -0.023 & -0.076 & -0.093 & -0.205 \\
$\mathrm{P}$ & 0.415 & 0.618 & 0.547 & 0.684 & 0.492 & 0.178 & 0.881 & 0.587 & 0.539 & 0.174 \\
\hline totBurned & -0.153 & -0.050 & -0.166 & 0.035 & -0.048 & -0.206 & 0.067 & 0.013 & -0.019 & -0.188 \\
$\mathrm{P}$ & 0.274 & 0.754 & 0.234 & 0.803 & 0.765 & 0.191 & 0.658 & 0.924 & 0.897 & 0.210 \\
\hline unburn & 0.097 & 0.119 & 0.074 & -0.019 & -0.186 & 0.148 & 0.052 & -0.036 & 0.131 & 0.197 \\
$\mathrm{P}$ & 0.504 & 0.474 & 0.607 & 0.894 & 0.263 & 0.364 & 0.740 & 0.804 & 0.395 & 0.202 \\
\hline
\end{tabular}

juv: juvenile hares, dev: developed hares, total: sum of juvenile and developed hares, intBurned: total hares in the intensely burned areas, modBurned : total hares in the moderately burned areas, unburned: total hares in the unburned areas, totBurned: sum of intBurned and modBurned

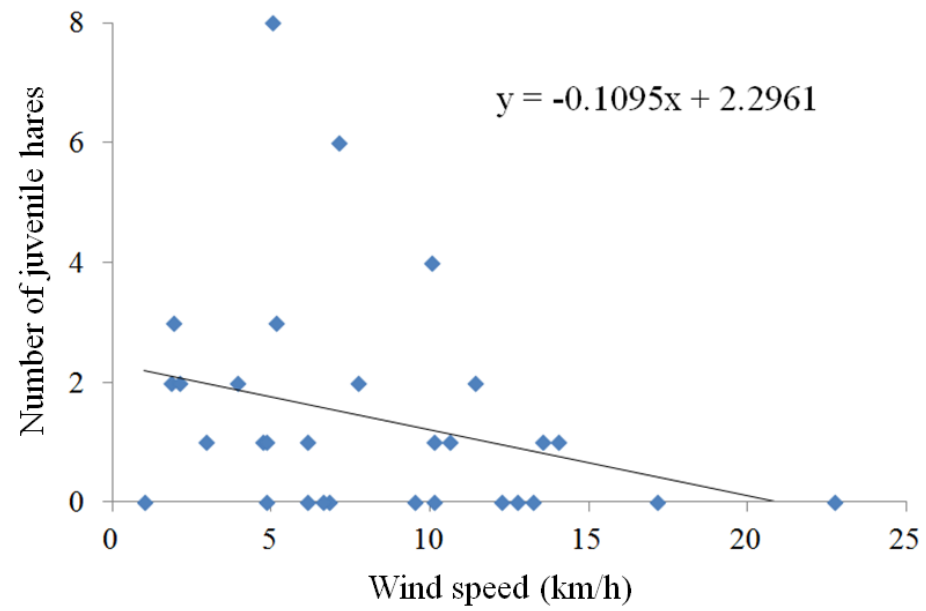

Figure 3. Total number of juvenile hares which were counted from the three transects in each visit in relation with wind speed

\section{Discussion}

Analyses on spotlight counts showed that wind speed and wind direction influenced counted hares in some cases. Similarly, Newman (1959) found that the number of cottontails observed during roadside counts was higher with decreasing wind speed. Wind causes the moving of vegetation and thus the ability of observer to detect the hares and especially the smaller juveniles appears to be decreased. Moreover the movable of vegetation may cause fear to juveniles and thus the decreasing of their movements. High speed winds have been associated with decreased activity in lagomorphs (Lechleitner, 1958; Smith, 1990; Villafuerte et al., 1993).

From the other side, the movement and the noise by the wind-blown vegetation apparently make the detection of the approaching vehicle more difficult for hares and thus 
hares may stay nearer to the road and thereby the probability of be counted is increased. Perhaps this is why a positive relationship was found, although not significant, between the intensity of the wind and the recorded developed hares, which as more experienced than juveniles may know that should go away when a car is approaching and this was observed during this study. Other studies have also found that the distance at which a mammal move away from an approaching human is negatively correlated with wind speed (Karlsson et al., 2007). Moreover, wind direction was also significantly associated with hares counted in intensely burned area, which tended to increase when the wind was blowing from the east direction, this means from the hare to vehicle (Fig. 1). The east wind appears to take away the noise under the circumstances of intensely burned area with a straighter west-east road than in other areas.

Analyses on spotlight counts indicated that no other weather or moon variable had an impact on the counted hares. Precipitation variation was relatively small and rainfall in the day of visit was below $2.5 \mathrm{~mm}$, under these conditions none important influence of rains was detected. These conditions provided us the opportunity to better examine the influences of temperature and moonlight. However, none appeared to have any effect on hare counts.

In our study area the steeply upland area and the thick vegetation do not permit the observation of hares at long distances as in open areas, thus in upland landscapes, such as the Kassandra Peninsula, the counting of hares seems to depend more on randomness: that is if a hare is close to the road at the time the car passes. Nevertheless, in flat landscapes hares can be observed at greater distances. In this case the observer's ability and hare's behaviour may have a higher importance for the detection, and may be more influenced by weather and moon. This may explain why in Britain it was proved that temperature reduced brown hare activity, with significantly fewer hares spotlighted when the temperature fell under $15^{\circ} \mathrm{C}$ (Barnes and Tapper, 1985). For other lagomorph species, Newman (1959) found that the number of cottontails counted increased with the decrease of temperature, and Rogowitz (1997) found that temperature had no significant effect on movements of white-tailed jackrabbits (Lepus townsendii).

Many nocturnal mammals react to increasing moonlight by restricting their movements and the use of open areas to avoid detection by predators (Kolb, 1992; Beier, 2006). In Ireland, moonlight negatively affected counts of Irish hare (Lepus timidus hibernicus) during winter in areas where the vegetation is usually short (Reid et al., 2007). The same was found for white-tailed jackrabbit that reduces its activity during periods of greater moonlight in grasslands (Rogowitz, 1997).

In our forested study area, the vegetation, even in burned areas a few months following the wildfire, provided adequate cover for hare, a fact that may decrease the detection probability by predators and the moonlight influence. A similar case may be that of snowshoe hares (Lepus americanus) which are less active in open areas during nights with increased moonlight in winter (Gilbert and Boutin, 1991; Griffin et al., 2005), but this was not found in the snow-free season when the vegetation cover and hiding opportunities were higher (Griffin et al., 2005). In contrast, black-tailed jackrabbits in northern Utah were more active when moonlight was more intensive during fall, winter and spring. During summer moonlight did not appear to influence jackrabbit activity (Smith, 1990).

In conclusion, only wind speed and direction had an influence on hare counts tending towards significance. Thus, the researcher should expect to see fewer juvenile hares in windy days, something that would not apply to developed hares. Yet if the wind is 
blowing from the hares towards vehicle the researcher is likely to count more hares. Temperature and moon did not influence spotlight counts. Precipitation also had no effect possibly due to its low variability in this study. In a future study, will be a need to test the method in relation to weather and moon in different ecotopes, especially concerning relief and vegetation structure.

Acknowledgements. The authors are grateful to the undergraduate students Kostas Demetriou, Apostolos Kastoris and Stelios Kyprou for their help with the hare counts.

\section{REFERENCES}

[1] Barnes, R.F.W., Tapper, S.C. (1985): A method for counting hares by spotlight. - Journal of Zoology 206: 273-276.

[2] Beier, P. (2006): Effects of artificial night lighting on terrestrial mammals. - In: Rich, C., Longcore, T. (eds) Ecological Consequences of Artificial Night Lighting. Island Press, Washington, DC, USA. pp. 19-42.

[3] Box, G.E.P., Jenkins G.M., Reinsel G.C. (2008): Time Series Analysis: Forecasting and Control. $-4^{\text {th }}$ Edition, Wiley.

[4] Bray, Y., Champely, S., Soyez, D. (2002): Age determination in leverets of European hare Lepus europaeus based on body measurements. - Wildlife Biology 8: 31-39.

[5] Brown, C.R., Peinke, D.M. (2007): Activity patterns of springhares from the Eastern Cape Province, South Africa. . - Journal of Zoology 272: 148-155.

[6] Chatfield, C. (2004): The Analysis of Time Series: An Introduction. - $6^{\text {th }}$ Edition. Chapman and Hall/CRC Texts in Statistical Science.

[7] Fafarman, K.R.,Whyte, R.J. (1979): Factors influencing nighttime roadside counts of cottontail rabbits. - Journal of Wildlife Management 43: 765-767.

[8] Gilbert B.S., Boutin S. (1991): Effect of moonlight on winter activity of snowshoe hares (Lepus americanus). - Arctic, Antarctic, and Alpine Research 23: 61-65.

[9] Gray, C.D., Kinnear, P.R. (2011): IBM SPSS 19 Made Simple. - Psychology Press, East Sussex, UK.

[10] Griffin, P.C., Griffin, S.C., Waroquiers, C., Mills, L.S. (2005) Mortality by moonlight: predation risk and the snowshoe hare. - Behavioral Ecology 16: 938-944.

[11] Heydon M.J., Reynolds JC, Short MJ (2000): Variation in abundance of foxes (Vulpes vulpes) between three regions of rural Britain, in relation to landscape and other variables. - Journal of Zoology 251: 253-264.

[12] Jammalamadaka, S.R., Lund, U.J. (2006): The effect of wind direction on ozone levels: a case study. - Environmental and Ecological Statistics 13: 287-298.

[13] Karlsson, J., Eriksson, M., Liberg, O. (2007): At what distance do wolves move away from an approaching human?. - Canadian Journal of Zoology 85: 1193-1197.

[14] Kie, J.G., Boroski, B.B. (1995): Using spotlight counts to estimate mule deer population size and trends. - California Fish and Game 81: 55-70.

[15] Kolb, H.H. (1992): The effect of moonlight on activity in the wild rabbit (Oryctolagus cuniculus). - Journal of Zoology 228: 661-665.

[16] Langbein, J., Hutchings, M.R., Harris, S., Stoate, C., Tapper, S.C., Wray, S. (1999): Techniques for assessing the abundance of brown hares Lepus europaeus. - Mammal Review 29: 93-116.

[17] Lechleitner, R.R. (1958): Movements, density and mortality in a black-tailed jackrabbit population. - Journal of Wildlife Management 22: 371-384.

[18] Newman, D.E. (1959): Factors influencing the winter roadside count of cottontails. Journal of Wildlife Management 23: 290-294. 
[19] Parkes, J.P. (2001): Methods to monitor the density and impact of hares (Lepus europaeus) in grasslands in New Zealand. - DOC Science Internal Series 8. Wellington, Department of Conservation. $13 \mathrm{p}$.

[20] Ralls, K., Eberhardt, L.L. (1997): Assessment of abundance of San Joaquin kit foxes by spotlight surveys. - Journal of Mammalogy 78: 65-73.

[21] Reid, N., McDonald, R.A., Montgomery, W.I. (2007) Mammals and agri-environment schemes: hare haven or pest paradise? - Journal of Applied Ecology 44: 1200-1208.

[22] Rogowitz, G.L. (1997): Locomotor and foraging activity of the white-tailed jackrabbit (Lepus townsendii). - Journal of Mammalogy 78:1172-1181.

[23] Scott, D.M., Waite, S., Maddox, T., Freer, R., Dunstone, N. (2005): The validity and precision of spotlighting for surveying desert mammal communities. - Journal of Arid Environments 61: 589-601.

[24] Smith, G. (1990): Home range and activity patterns of black-tailed jackrabbits. - Great Basin Nat 50: 249-256.

[25] Strauß, E., Grauer, A., Bartel, M., Klein, R., Wenzelides, L., Greiser, G., Muchin, A., Nösel, H.,Winter, A. (2008): The German wildlife information system: population densities and development of European hare (Lepus europaeus PALLAS) during 20022005 in Germany. - European Journal of Wildlife Research 54: 142-147.

[26] Sunde, P., Jessen, L. (2013): It counts who counts: an experimental evaluation of the importance of observer effects on spotlight count estimates. - European Journal of Wildlife Research 59: 645-653.

[27] Tizzani, P., Menzano, A., Dematteis, A., Meneguz, P.G. (2013): Methodological problems related to spotlight count as a census technique for Lepus europaeus in an alpine environment. - Acta Theriologica 59: 271-276.

[28] Verheyden, C. (1991): A spotlight, circular-plot method for counting brown hares in the hedgerow system. - Acta Theriologica 36:255-265.

[29] Villafuerte, R., Kufner, M.B., Delibes, M., Moreno, S. (1993): Environmental factors influencing the seasonal daily activity of the European rabbit (Oryctolagus cuniculus) in a Mediterranean area. - Mammalia 57(3): 341-348. 